\title{
Çocuklarda radius başı ve olekranon kırıkları
}

\author{
Fracture of radial head and olecranon in children
}

\author{
Fuat Bilgili, Mehmet Demirel
}

İstanbul Üniversitesi İstanbul Tıp Fakültesi, Ortopedi ve Travmatoloji Anabilim Dalı, İstanbul

Eklem içi radius başı kırığı belirsiz klinik ve radyolojik bulgulara sahip olduğu için, bu kırığın teşhisi zordur. Doğru tanı ve uygun tedavi planı için direkt grafiye ek olarak manyetik rezonans görüntüleme ve bilgisayarlı tomografi tercih edilmelidir. Eklem içi radius başı kırıklarının, eklem dışı kırıklara göre daha yüksek komplikasyon oranları ve daha fazla revizyon cerrahisi gereksinimi vardır. Monteggia benzeri yaralanmalarda altı temel lezyon tanımlanabilir ve bunların herbiri tedavi edilmelidir: ulna kırığı, radyohumeral çıkık, ulnohumeral çıkık, proksimal radyoulnar çıkık, radius kırığı ve distal radyoulnar eklem\interosseöz membran lezyonu. Monteggia eşdeğer lezyonlarda öncelikli tedavi kapalı redüksiyondur; ancak redüksiyonun sağlanamaması durumunda cerrahi tedavi önerilmiştir. Olekranon kırıkları saf apofiz ve metafizyel olekranon kırıkları olarak iki ana kategoride sınıflandırılır. Ek yaralanmaların da olabileceği düşünüldüğü için, deplase olekranon kırıklarının tedavisi cerrahidir.

Anahtar sözcükler: kırıklar; olekranon; radius başı; çocuklar

\section{RADIUS BAŞI KIRIKLARI}

Proksimal radius başı ve boyun kırıkları, çocukluk çağında oldukça nadir görülmekle beraber, tüm pediatrik dirsek yaralanmalarının \%4-16'sını, tüm çocuk kırıklarının ise \%1'inden daha azını oluşturur. Bu kırıkların büyük çoğunluğu eklem dışıdır ve sıklıkla proksimal radiusun metafizer bölgesini içerir. Ayrıca, tüm proksimal radius yaralanmalarının \%10'undan daha azı radius başının eklem yüzeyini etkiler. ${ }^{[1]}$

Çocukluk çağında, eklem içi radius başı (EiRB) kırılarına, erişkin döneme kıyasla oldukça az rastlanmaktadır. Bunun nedeni olarak, çocukluk çağında proksimal epifiz kapanmaya başlayana kadar (erkeklerde
Intra-articular radial head fractures are difficult to diagnose due to ambiguous clinical and radiological findings. To achieve the correct diagnosis and plan the correct treatment, magnetic resonance imaging and computed tomography should be performed in addition to plain X-rays. Intra-articular radial head fractures have a higher rate of complication and need for revision surgeries compared to extra-articular fractures. Monteggia-like injuries can be defined as 6 basic lesions all of which must be treated: Ulnar fracture, radiohumeral dislocation, ulnohumeral dislocation, proximal radioulnar dislocation, radial fracture, and distal radioulnar joint/interosseous membrane lesion. In Monteggia equivalent lesions closed reduction is preferred initially, however, surgical treatment is advised if reduction cannot be achieved. Olecranon fractures are classified into 2 main types as pure apophyseal and metaphyseal olecranon fractures. Displaced olecranon fractures are treated surgically, keeping in mind additional injuries.

Key words: fractures; olecranon; radial head; children

- İletişim adresi: Doç. Dr. Fuat Bilgili, İstanbul Üniversitesi İstanbul Tıp Fakültesi, Ortopedi ve Travmatoloji Anabilim Dalı, İstanbul Tel: 0212 - 4142000 / 31511 e-posta: fuat.bilgili@istanbul.edu.tr

- Geliş tarihi: 2 Şubat 2019 Kabul tarihi: 2 Şubat 2019

ortalama 14-15 yaş, kızlarda ortalama 12-14 yaş) radius başının büyük ölçüde kıkırdak yapıda olması ileri sürülmektedir. ${ }^{[2]}$

Çocuklarda EiRB kırıkları, gerek nadir olmaları gerekse belirsiz klinik bulgulara sahip olmaları nedeniyle, tanı konulması oldukça zor yaralanmalardır. Waters ve ark..$^{[3]}$ bu nadir kırıkları "TRASH" (The Radiographic Appearance Seemed Harmless) lezyonlarının bir alt grubu olarak değerlendirmişler ve radyografideki selim görünümlerinden dolayı kolaylıkla göz ardı edilebileceklerine dikkat çekmişlerdir. Bu tip kırıklar, çoğu olguda eklem yüzeyinde önemsiz bir kemik parçası olarak göründüğünden dolayı, eklem içi kırık komponentinin tespit edilmesi oldukça zordur (Şekil 1 ve 2). 


\section{(a)}
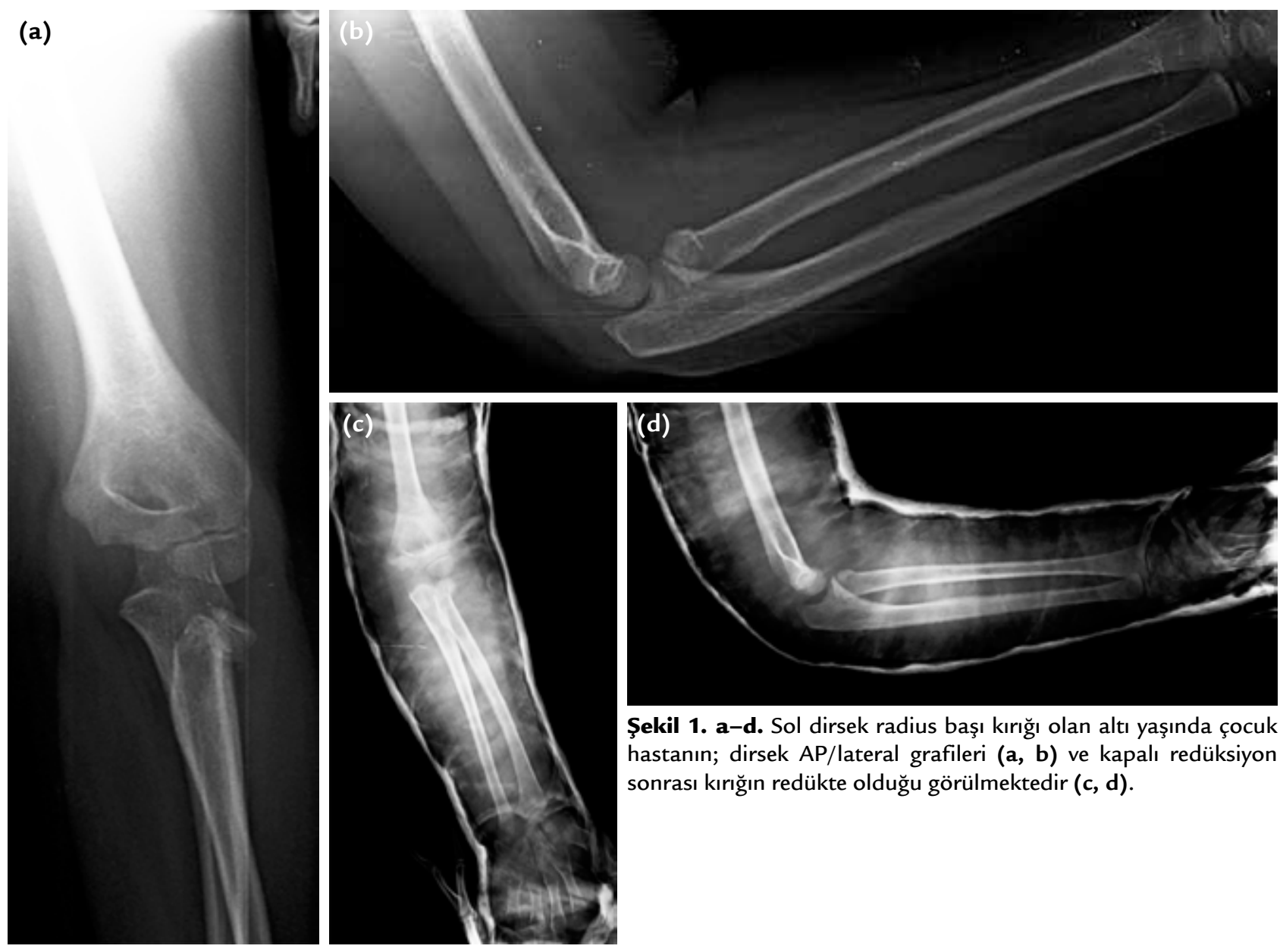

Şekil 1. a-d. Sol dirsek radius başı kırığı olan altı yaşında çocuk hastanın; dirsek AP/lateral grafileri $(\mathbf{a}, \mathbf{b})$ ve kapalı redüksiyon sonrası kırığın redükte olduğu görülmektedir (c, d).

Literatür taramamıza göre ${ }^{[1,3-5]}$, EiRB kırı̆̆ından şüphe edildiği takdirde, doğru tanı ve uygun tedavi planı için manyetik rezonans (MR) görüntüleme ve bilgisayarlı tomografi (BT) gibi ileri görüntülüme yöntemleri tercih edilmelidir. Ayrıca, standart anterior-posterior (AP) ve lateral radyografilere ek olarak Greenspan lateral grafi, radius başının daha net olarak değerlendirilmesine olanak sağlayabilir. MR görüntüleme ve cerrahi girişim hekimin eklem tutulumunun derecesini daha iyi anlamasına yardımcı olabilir ve çevredeki yumuşak dokuların bütünlüğü ile ilgili önemli bilgiler sağlar. ${ }^{[3]}$

Özgün klinik ve radyografik bulgulara sahip bir kırık tipi olarak, EiRB kırıkları, eklem dışı radius başı kırıklarına (EDRB) göre daha yüksek komplikasyon oranları ile ilişkilidir. EiRB kırıklarında artmış komplikasyon oranlarına annüler bağın kopması ve/veya büyüme plağının erken kapanmasının neden olabileceği üzerinde durulmaktadır. ${ }^{[4,5]}$ Leung ve Peterson ${ }^{[4]}$,
EiRB kırığı olan yedi çocuk hastadan oluşan olgu serilerinde, tüm hastalarda radiusun göreceli olarak kısalmasına yol açan erken fiziyel kapanma geliştiğine ve bu olguların dördünde cerrahi tedavi gerektiğine dikkat çekmişlerdir. Yazarların elde ettikleri sonuçlar göstermektedir ki, açık bir büyüme plağı varlığında, radius başının eklem yüzeyini tutan kırıklar genellikle ön görülebilir derecede kötü sonuçlarla sonuçlanmaktadır.

Benzer şekilde, Van Zeeland ve ark. ${ }^{[5]}$, EiRB kırığı olan yedi pediatrik olgunun tamamında, cerrahi tedavi gerektirecek düzeyde ilerleyici eklem yarı çıkığı ve ciddi kıkırdak dejenerasyonu ile ilişkili klinik bulguların varlığını bildirmişlerdir. Cerrahi tedavi uyguladıkları altı olgunun dördünde annüler bağın bütünlüğünün bozulduğunu gözlemleyen yazarlar, ilerleyici radyokapitellar yarı çıkığı gelişen EíRB kırığı olgularında annüler bağ tamirinin yarı çıkık gelişiminin engellenmesinde yardımcı olabileceğini ileri sürmüşlerdir. 

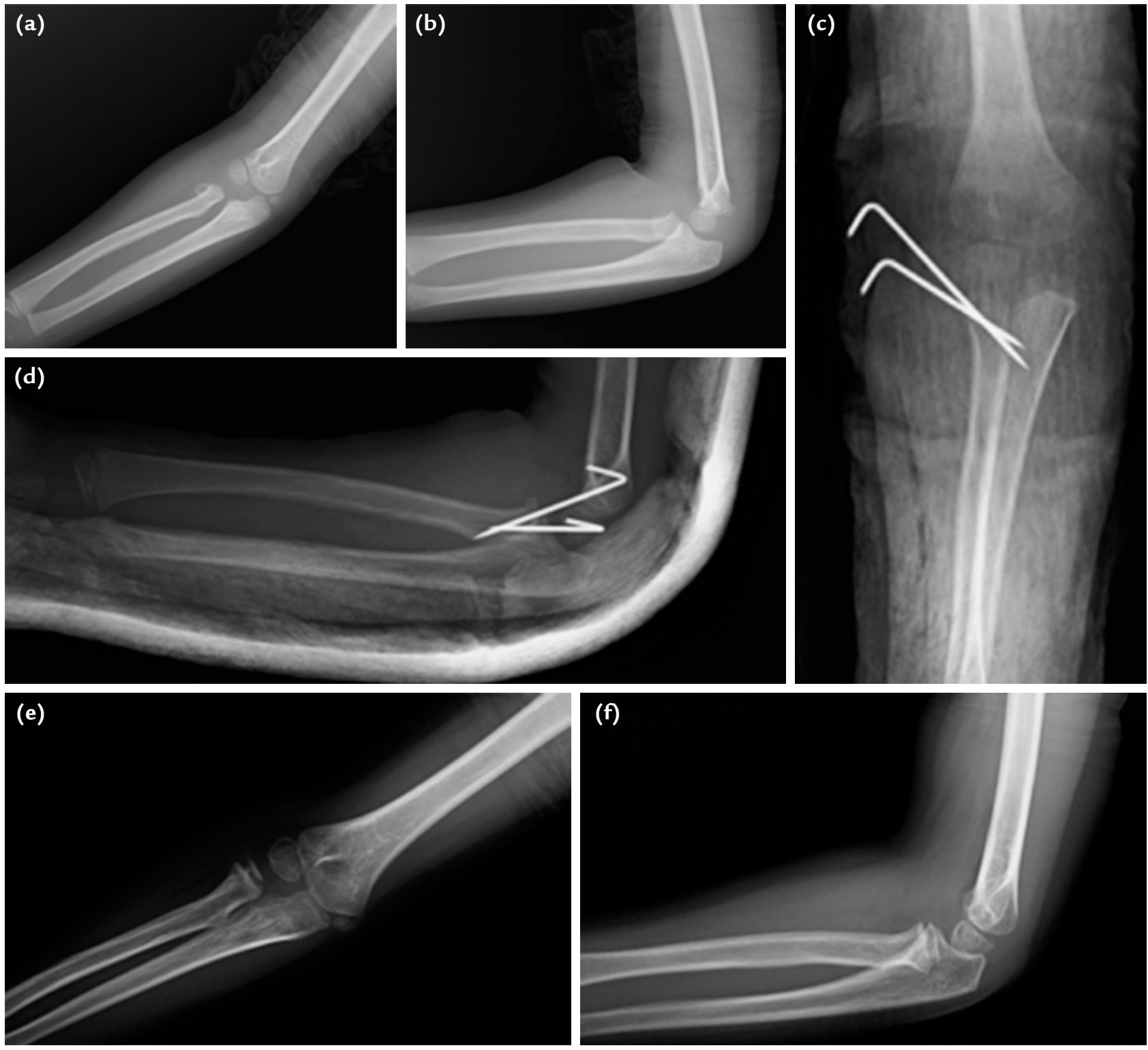

Şekil 2. a-f. Sağ dirsek radius başı kırığı olan hastanın; ameliyat öncesi (a, b), açık redüksiyon ve K-teli ile osteosentez sonrası (c, d) ve bir yıl sonraki takip sonucu $(e, f)$ görülmektedir.

Tanı konulması zor ve komplikasyonlara oldukça açık olan EiRB kırıkları kapsamında, literatürde yer alan en güncel çalışmalardan birinde, Ackerson ve ark. ${ }^{[1]}$, iskelet olgunluğuna ulaşmamış olgularda EiRB kırıkları ile EDRB kırıklarının komplikasyon oranlarını karşılaştırmayı amaçlamıştır. Araştırmaya dahil edilen 311 hastanın 12'sinde EiRB kırığı mevcutken, geriye kalan 299 hasta EDRB kırığı nedeniyle tedavi almıştır. Komplikasyon oranları, EiRB kırı̆ıı olan olgularda \%50 olarak tespit edilirken, EDRB kırığı olan olgularda sadece \%1,34 olarak saptanmıştır. Ayrıca, EiRB kırı̆̆ı olan olguların büyük çoğunluğunda revizyon cerrahisi (\%25) gerekmesine rağmen, EDRB kırığı olan olguların hiçbirinde cerrahi gereksinim gözlenmemiştir. Yazarlar sonuç olarak, EDRB kırıkları ile karşılaştıııldığında, EIRB kırıklarının belirgin olarak daha fazla komplikasyon oranları ve daha fazla revizyon cerrahisi gereksinimi ile ilişkili olduğu sonucuna varmışlardır.

Pediatrik EiRB kırıkları ile ilişkili yüksek komplikasyon oranları ve artmış revizyon cerrahisi gereksinimi, ortopedistlerin bu kırık tipine dair farkındalığının artmasını gerektirmektedir. 


\section{Monteggia Benzeri Lezyonlar}

Literatürde dünden bugüne, Monteggia kırıkları için en sık kullanılan sınıflama sistemi Bado sınıflaması olmuştur. Bunun için en geçerli neden, bu sınıflama sisteminin cerrahi pratiğine uygulanabilirliğidir. Bununla birlikte, yıllar içerisinde radius başı kırıkları, koronoid kırıkları ve kombine radius başı ve koronoid kırıkları gibi ek yaralanmalar, Monteggia benzeri yaralanmaların sınıflandırılmasının daha da karmaşık hale gelmesine neden olmuştur. Monteggia benzeri lezyonlar veya Monteggia eş değeri yaralanmaların hepsini Bado sınıflandırması ile değerlendirmek mümkün değildir. ${ }^{[6]} \mathrm{Bu}$ nedenle, Monteggia kırı̆ğ eponimi, proksimal ulna ve radiusun kompleks kırık ve çıkıklarının çeşitli paternlerini içermekte olup, henüz literatürde yeterince tanımlanmamıştır. ${ }^{[7]}$

Diğer yazarlar, Monteggia eşdeğeri olarak radius başı ve koronoid kırıkları gibi ek yaralanmalar içeren Monteggia lezyonlarını tanımlamaktadırlar. ${ }^{[7,8]}$ Diğer taraftan, Giannicola ve ark.'na ${ }^{[7]}$ göre, Monteggia benzeri lezyon çerçevesinde, aşağıdaki altı temel lezyon tanımlanabilir ve bunların her biri tedavi edilmelidir:

- Ulna kırığı

- Radyohumeral çıkık

- Ulnohumeral çıkık

- Proksimal radyoulnar çıkık

- Radius kırı̆̆ı

- Distal radyoulnar eklem\interosseöz membran lezyonu

Bu kritik lezyonların çeşitli kombinasyonları, tedavilerinin karmaşıklığını ve çeşitliliğini açıklayabilir. ${ }^{[7]}$

Her ne kadar, Bado Tip II, III ve IV Monteggia kırıklarının eşdeğerlerinin olmadığını öne sürmüş olsa $\mathrm{da}$, çeşitli araştırmacılar kırık paterni, biyomekanik ve yaralanma mekanizmalarına dayanarak bu tiplere ait eşdeğer lezyonları tanımladılar. ${ }^{[9-11]}$ Penrose ${ }^{[10]}$, posterior dirsek çıkıklarının Tip II eşdeğeri olarak düşünülebileceğini bildirdi. Benzer şekilde, Wright tarafından tanımlanan $^{[11]}$ ve Tip III lezyonlarından sorumlu tutulan hiperekstansiyon ve lateral varus stresini içeren yaralanma mekanizması göz önünde bulundurulduğunda, Ravessoud tarafindan tanımlanan ${ }^{[12]}$ varus kusurlu dizilimi ile ulna oblik kırığı ve ipsilateral deplase lateral kondil kırığı, Tip III eşdeğeri olarak düşünüldü. Ayrıca, Arazi ve ark. ${ }^{[13]}, 13$ yaşında bir kız çocuğunda Tip IV eş değeri olarak değerlendirilebilecek olan, aynı tarafta distal humerus ve distal radius kırığının eşlik ettiği Tip IV Monteggia lezyonu olgusunu rapor ettiler. Tip II, III ve IV eşdeğerlerine ek olarak, Arora ve ark. ${ }^{[14]}$, proksimal ulna kırığına eşlik eden aynı taraflı suprakondiller humerus kırı̆̆ı olan altı yaşındaki kız hastanın mevcut kırık paterninin, Tip I Monteggia benzeri lezyon olarak düşünülebileceğini ileri sürdü.

Monteggia benzeri lezyonlara yönelik tedavi yaklaşımı üzerine yapılan bir geriye dönük olgu serisinde, Güven ve ark. ${ }^{[15]}$, Tip I ve Tip III eşdeğer lezyonu olan toplam 13 çocuk hastada konservatif ve cerrahi tedavi sonuçlarını değerlendirdiler. Açık kırıklı çıkık nedeniyle acil debridman ve irrigasyon uyguladıkları bir hasta dışında, tüm hastalarda öncelikle kapalı redüksiyon denediler. Sekiz hastada $(\% 61,5)$ konservatif tedaviyle yeterli redüksiyon elde ederlerken, dört hastada $(\% 30,8)$ redüksiyon sağlanamaması nedeniyle, yaralanmadan sonra ilk 24 saat içinde cerrahi girişim uyguladıklarını belirttiler. Ortalama takip süresi 4,1 yıl (dağılım 2-7 yıl) olan hastaların tamamında kaynama elde ettiler. Konservatif olarak tedavi ettikleri hastaların hiçbirinde radius başında redüksiyon kaybıyla karşılaşmadıklarını ve dirsek hareketlerinde kısıtlılık gözlenmediğini bildirdiler. Yazarlar, konservatif tedavi gören hastaların hepsinde fonksiyonel sonuçların iyi olduğunu belirtmişlerdir. Ayrıca, cerrahi tedavi uygulanan dört hastada fonksiyonel sonuçların iyi olmasına rağmen, açık kırıklı çıkığı olan bir olguda kötü fonksiyonel sonuç ile karşılaştıklarını kayıt altına almışlardır. Araştırmacılar, çocuklardaki Monteggia eşdeğer lezyonlarda öncelikli tedavinin kapalı redüksiyon olduğu ancak redüksiyonun sağlanamaması durumunda cerrahi tedavinin gündeme gelebileceği çıkarımını yapmışlardır.

Sonuç olarak, derlememizden anlaşılabileceği gibi, Monteggia benzeri lezyonlar çocukluk çağının oldukça nadir yaralanmalarıdır. Literatür taramamıza göre, pediatrik hasta grubunda konu üzerine yapılmış daha fazla geniş olgu serilerine gereksinim vardır. Bu lezyonların tedavilerinin, hastanın yaşı, yaralanma mekanizması ve mevcut kırık paterni göz önünde bulundurularak yapılması gerektiği kanaatindeyiz.

\section{OLEKRANON KIRIKLARI}

Olekranon kırıkları, çocuklarda tüm dirsek kırıklarının yaklaşık \%5'ini oluşturmakta ve genellikle hiperekstansiyon yaralanması sonucu oluşmaktadır. Hiperekstansiyon yaralanmaları sıklıkla ek dirsek yaralanmalarına yol açar. Ek yaralanmanın tipini belirleyen esas faktör koronal düzlemdeki kuvvetin yönüdür. ${ }^{[16]}$

Sağlıklı çocuklarda olekranon kırıkları iki ana kategoride sınıflandırılır: genellikle küçük çocukları etkileyen saf apofiz ve daha büyük çocukları etkileyen, epifize komşu büyük bir metafizer parça ile karakterize olan metafizyel olekranon kırıkları. ${ }^{[17]}$ Bu kırıklara doğrudan veya dolaylı bir mekanizma neden olabilir. Direkt travma sonucu meydana gelen bu kırıklar sıklıkla sağlıklı 


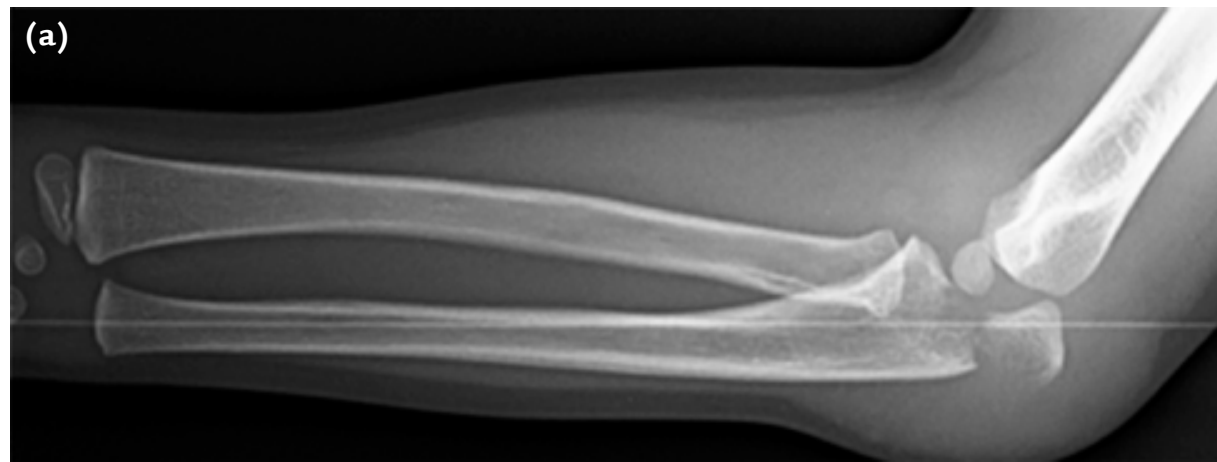

(b)
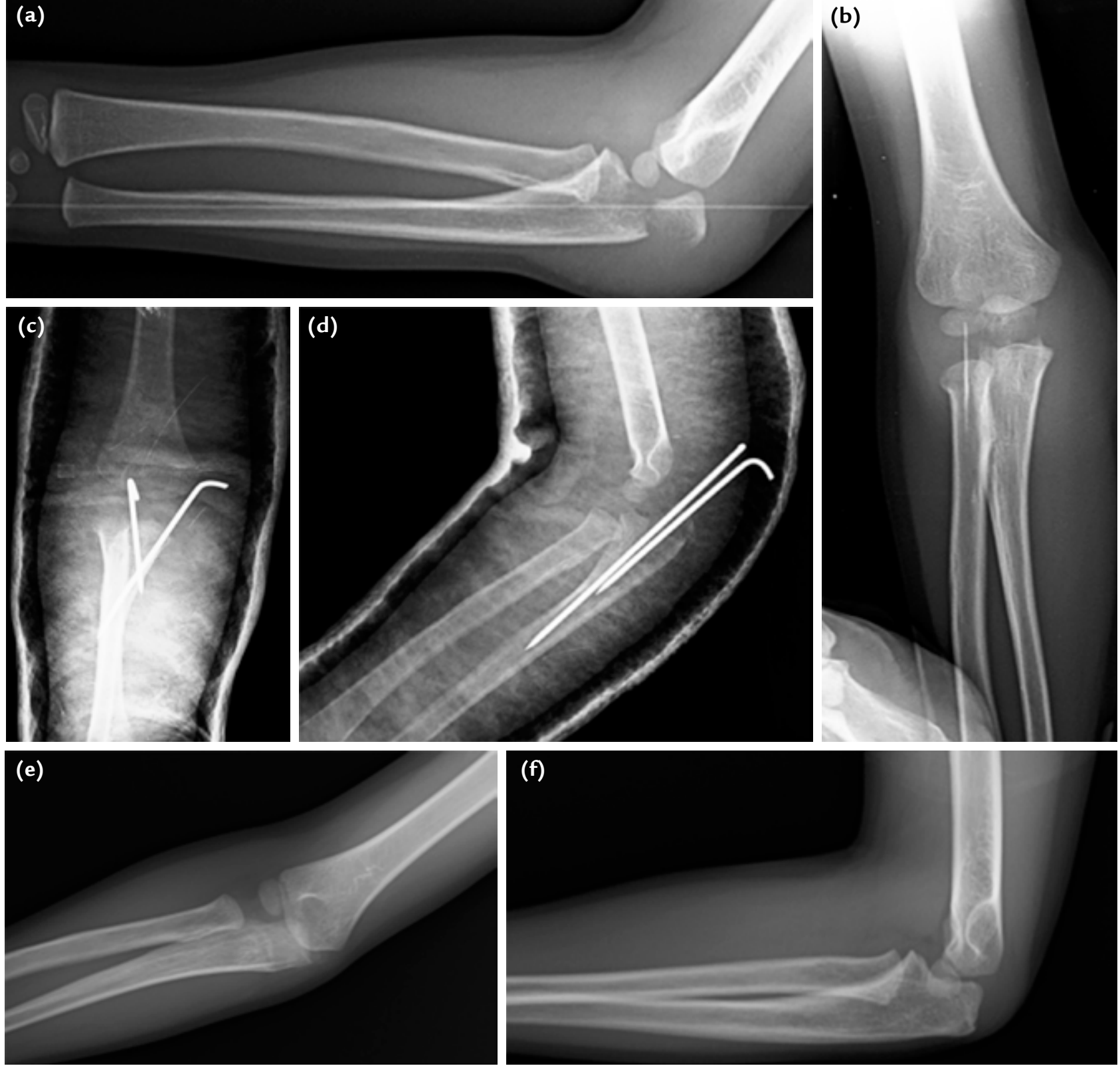

Şekil 3. a-f. Yer değiş̧tirmiş olekranon kırığı olan dört yaşındaki bir hastanın; ameliyat öncesi AP/lateral grafileri (a, b), ameliyattan bir gün sonra $(c, d)$ ve bir yıl sonraki grafileri $(e, f)$ görülmektedir.

çocukları etkiler. Bunlar çoğunlukla $2 \mathrm{~mm}$ 'den daha fazla deplase olmuş olekranon kırıklarıdır ve genellikle tek bir kırık çizgisi ile karakterizedir. ${ }^{[18]}$

Dolaylı mekanizma ile meydana gelen olekranon kırıları ise sıklıkla osteogenezis imperfektalı çocuklarda görülen triseps kasının ani kasılması sonucu olekranonun tepesinde meydana gelen avulsiyon tipi kırıklardır. ${ }^{[19]}$

Çocuklarda radyolojik olarak olekranon kırıklarının tanısını koymak zordur. Özellikle küçük çocuklarda tek radyografik bulgu, küçük bir kemik parçasının karşı dirsekle karşılaştırıldığında ayrık olarak izlenmesi olabilir.

Deplase olekranon kırıklarının tedavisi hemen her zaman açık redüksiyon ve internal tespit ile cerrahi tedavidir. ${ }^{[20]}$ Literatürde, hangi cerrahi tekniğin uygulanması gerektiğine dair kesin endikasyon söz konusu değildir. Bununla birlikte, en sık kullanılan cerrahi teknikler plak-vida, kompresyon vidaları ve gergi bandı yöntemidir (Şekil 3). ${ }^{[16]}$ 
Kirschner teli (K-teli) ile osteosentezde, telin çapı küçük olduğundan büyüme plağı hasarı riski oldukça azdır. ${ }^{[21]}$ Diğer taraftan, K-telinin çapından daha büyük olan, 3,5 mm çapındaki kanüle vida için, fiz hasar riski daha yüksektir; ancak yine de göz ardı edilebilir. [22]

\section{KAYNAKLAR}

1. Ackerson R, Nguyen A, Carry PM, Pritchard B, HadleyMiller N, Scott F. Intra-articular Radial Head Fractures In the Skeletally Immature Patient: Complications and Management. J Pediatr Orthop 2015;35(5):443-8. Crossref

2. Tibone JE, Stoltz M. Fractures of the radial head and neck in children. J Bone Joint Surg Am 1981;63(1):100-6. Crossref

3. Waters PM, Beaty J, Kasser J. Elbow "TRASH" (the radiographic appearance seemed harmless) lesions. J Pediatr Orthop 2010;30(Suppl 2):S77-81. Crossref

4. Leung AG, Peterson HA. Fractures of the proximal radial head and neck in children with emphasis on those that involve the articular cartilage. J Pediatr Orthop 2000;20(1):7. Crossref

5. Van Zeeland NL, Bae DS, Goldfarb CA. Intra-articular radial head fracture in the skeletally immature patient: progressive radial head subluxation and rapid radiocapitellar degeneration. J Pediatr Orthop 2011;31(2):124-9. Crossref

6. Jungbluth P, Tanner S, Schneppendahl J, Grassmann JP, Wild M, Hakimi M, WindolfJ, Laun R. The challenge of Monteggialike lesions of the elbow: mid-term results of 46 cases. Bone Joint J 2018;100-B(2):212-8. Crossref

7. Giannicola G, Greco A, Sacchetti FM, Cinotti G, Nofroni I, Postacchini F. Complex fracture-dislocations of the proximal ulna and radius in adults: a comprehensive classification. J Shoulder Elbow Surg 2011;20(8):1289-99. Crossref

8. Rehim SA, Maynard MA, Sebastin SJ, Chung KC. Monteggia fracture dislocations: a historical review. J Hand Surg 2014;39(7):1384-94. Crossref

9. Canale ST, Fractures and dislocations in children. In: Canale ST, editor. Campbell's Operative Orthopaedics. Vol. 2, 10th ed. Philadelphia: Mosby; 2003. pp.1391-568. 10

Penrose JH. The Monteggia fracture with posterior dislocation of the radial head. J Bone Joint Surg Br 1951;33-B(1):65-73. Crossref
11. Wright PR. Greenstick fracture of the upper end of the ulna with dislocation of the radio-humeral joint or displacement of the superior radial epiphysis. J Bone Joint Surg Br 1963;45$B(4): 727-31$. Crossref

12. Ravessoud FA. Lateral condylar fracture and ipsilateral ulnar shaft fracture: Monteggia equivalent lesions? J Pediatr Orthop 1985;5(3):364-6. Crossref

13. Arazi M, Öğün TC, Kapicioğlu MS. The Monteggia lesion and ipsilateral supracondylar humerus and distal radius fractures. J Orthop Trauma 1999;13(1):60-3. Crossref

14. Arora S, Sabat D, Verma A, Sural S, Dhal A. An unusual Monteggia equivalent: a case report with literature review. J Hand Microsurg 2011;3(2):82-5. Crossref

15. Güven M, Eren A, Kadioğlu B, Yavuz U, Kilinçoğlu V, Ozkan K.. The results of treatment in pediatric Monteggia equivalent lesions. Acta Orthop Traumatol Turc 2008;42(2):90-6.

16. Persiani P, Ranaldi FM, Graci J, De Cristo C, Zambrano A, D'Eufemia P, Martini L, Villani C. Isolated olecranon fractures in children affected by osteogenesis imperfecta type I treated with single screw or tension band wiring system: Outcomes and pitfalls in relation to bone mineral density. Medicine 2017;96(20):e6766. Crossref

17. Wilkins KE. Fractures involving the proximal apophysis of the olecranon. In: Rockwood CA Jr, Wilkins KE, King RE, editors. Fractures in Children, 3rd ed. Philadelphia: JB Lippincott; 1991. pp.751-7.

18. Gicquel Ph, De Billy B, Karger CS, Clavert JM. Olecranon fractures in 26 children with mean follow-up of 59 months. J Pediatr Orthop 2001;21(2):141-7. Crossref

19. Caterini R, Farsetti P, D'Arrigo C, Ippolito E. Fractures of the olecranon in children. Long-term follow-up of 39 cases. J Pediatr Orthop B 2002;11(4):320-8. Crossref

20. Arbes $S$, Platzer $P$, Vécsei $V$, Surgical treatment of olecranon fractures in children. Eur J Orthop Surg Traumatol 2012;22(3):209-12. Crossref

21. Yung PSH, Lam CY, Ng BKW, Lam TP, ChengJCY. Percutaneous transphyseal intramedullary Kirschner wire pinning: a safe and effective procedure for treatment of displaced diaphyseal forearm fracture in children. J Pediatr Orthop 2004;24(1):712. Crossref

22. Li WC, Xu RJ. Comparison of Kirschner wires and AO cannulated screw internal fixation for displaced lateral humeral condyle fracture in children. Int Orthop 2012;36(6):1261-6. Crossref 